\title{
Peripheral intravenous line skills among pediatrics and medicine-pediatrics residents at a single tertiary care center
}

\author{
Krishna Acharya, ${ }^{1}$ Amanda Weaver, ${ }^{2}$ Jingyun Li, ${ }^{3}$ Xinyu Tang, ${ }^{4}$ Franscesca Miquel-Verges ${ }^{5}$ \\ ${ }^{1}$ Department of Pediatrics, University of Arkansas for Medical Sciences, Little Rock, AR, USA \\ ${ }^{2}$ Neonatal Intensive Care Unit, Arkansas Children's Hospital, Little Rock, AR, USA \\ ${ }^{3}$ Department of Pediatrics, College of Medicine, University of Arkansas for Medical Sciences, Little Rock, AR, USA \\ ${ }^{4}$ Department of Pediatrics, College of Medicine, University of Arkansas for Medical Sciences, Little Rock, AR, USA \\ ${ }^{5}$ Section of Neonatology, Department of Pediatrics, University of Arkansas for Medical Sciences, Little Rock, AR, USA
}

Correspondence: Krishna Acharya, University of Arkansas for Medical Sciences, Department of Pediatrics, Section of

Neonatology, Arkansas Children's Hospital, 1 Children's Way, Slot 512-5, Little Rock, AR 72202, USA. Email: KKAcharya@uams.edu

\begin{abstract}
Objectives: To assess pediatrics residents' self-reported competency in placing peripheral intravenous (IV) lines at baseline; to conduct a peripheral intravenous simulationbased training session for residents; and to measure peripheral intravenous (PIV) competency on manikins following the intervention as well as changes in scores of self-reported knowledge, confidence, and success from baseline.
\end{abstract}

Methods: Pediatrics residents at Arkansas Children's Hospital participated in the study and completed a baseline survey assessing PIV knowledge, confidence, and success, and then attended a PIV training session in 2011. Training included a didactic session followed by demonstration on manikins. Residents completed an immediate postintervention survey and a follow-up survey at 3 months. Primary outcomes were successful demonstrations of PIV skills as assessed by a PIV competency checklist. Secondary outcomes were increased self-reported scores of knowledge, confidence, and success with PIV placement. Forty-two residents completed the pre-intervention survey. Thirty-two finished the educational session and completed the initial survey. Thirty-one completed the survey at 3 months.

Results: Thirty (94\%) residents were successful in demonstrating PIV competency. Participants' self-reported knowledge and confidence in PIV line placement improved significantly after this educational session, both immediately after and at 3 months, but overall confidence remained low, and there was no increase in success.

Conclusions: Pediatric residents' self-reported competency with PIV placement is low. PIV training achieves residents' competency on a manikin, and improves perceived knowledge and confidence scores but overall confidence remains low. Such training should be supported by opportunities to place PIVs on real patients.

Keywords: Peripheral intravenous, pediatrics residents, simulation

\section{Introduction}

With the changing trends in medicine, residents are performing fewer procedures than they did 2 decades ago., ${ }^{1,2}$ Residents often learn procedures 'on-the-go', and receive less formal procedural training and supervision compared to nurses. ${ }^{2}$ In general, residency training is moving toward a less hands-on approach, with greater reliance on ancillary staff. While this multidisciplinary approach promotes individual expertise and patient safety, it runs the risk of absolving residents of necessary skills.
The Pediatrics Residency Review Committee of the Accreditation Council of Graduate Medical Education (ACGME) requires all pediatrics residents to receive sufficient training in 16 procedural skills, ${ }^{3}$ one of which is the placement of PIV lines. U.S. and international studies ${ }^{1,4-6}$ both report that house-officers receive considerable clinical experience with placing peripheral intravenous lines in adult patients, but data for pediatric patients are limited..$^{7-10}$ According to one study, only a third of senior pediatrics residents 
expressed confidence in their ability to obtain intravenous access. $^{8}$ No data are available on current pediatrics residents' experience with PIV skills or their perceived importance of this skill.

Pediatrics residency program directors regard IV access as an extremely important procedure for residents to learn, yet they express little confidence in their residents' ability to obtain PIV access. ${ }^{9}$ In the United States, two-thirds of current pediatric graduates will go on to practice general pediatrics. ${ }^{11,12}$ A survey of U.S. general pediatricians showed that $95 \%$ consider venipuncture a necessary skill, ${ }^{13}$ and that two-thirds of general pediatricians perform venous cannulation in their practice. ${ }^{14}$ Even for the residents who go on to practice in larger academic centers or pursue a fellowship, their proficiency in this skill may be a valuable resource.

Given that peripheral intravenous skill is potentially valuable to both the generalist and the specialist in pediatric practice, and the limited available data on pediatrics residents' competency and experience with this skill, we undertook this study with the following objectives: 1) To conduct a survey of pediatric and medicine-pediatrics residents' selfreported knowledge, confidence, and success in obtaining peripheral intravenous access at baseline; 2) To teach pediatrics and medicine-pediatrics residents PIV access skills via a didactic lesson followed by a simulation-based practice session; and 3) To assess residents' skill competency on manikins and scores of self-reported knowledge, confidence, and success in obtaining IV access immediately after and at 3 months post intervention.

\section{Method}

\section{Setting}

Arkansas Children's Hospital is a large, 370-bed tertiary care center located in Little Rock, AR. Our pediatrics residency program is a fully accredited, large-sized training program. In our hospital, nurses usually place PIV lines, and several skilled IV nursing teams are in place. Pediatrics residents have the opportunity to practice their PIV skills on rotations such as anesthesia, "procedure month", emergency room, neonatal intensive care, and pediatric intensive care, but are not expected to place PIVs unless they so desire.

\section{Study design}

We conducted a single-group pre- and post-intervention study using a convenience sample of residents. The Institutional Review Board at University of Arkansas for Medical Sciences approved this study. We invited 93 pediatrics and 17 medicine-pediatrics residents at the University of Arkansas for Medical Sciences and Arkansas Children's Hospital to participate in the study. Following informed consent, participants completed the baseline survey. Surveys were designed by the investigators (KA, FMV, and AW).

\section{Surveys}

\section{Baseline survey}

The baseline survey assessed self-reported knowledge, confidence, and success with PIV placement. We administered the survey online at the beginning of the academic year (August-September 2011) and collected the following information: 1) Knowledge with PIV placement was assessed by 4 questions with yes/no responses, scored from 0 4 with 4 indicating highest knowledge, which was measured by the questions: If you had to start a PIV in a pediatric patient, would you know how to: a) Prepare necessary equipment, b) Select appropriate needle size, c) Select appropriate site for needle insertion, d) Appropriately secure PIV once it is inserted; 2) Success with PIV placement was measured by 1 question and scored from 0-3 with 0 indicating success less than $25 \%$ of the time, 1 indicating success $25-50 \%$ of the time, 2 indicating success $50-75 \%$ of the time, and 3 indicating success greater than $75 \%$ of the time. The baseline survey also collected information on residents' perceived importance of PIV placement competency, prior training in PIV placement, and experience with PIV placement before and during residency on real patients. We removed residents from the subset sample for success with PIV placement if they reported 'no PIVs placed' before and during residency.

\section{Educational session}

We invited residents who completed the baseline survey to a training session. Two instructors (FMV, AW), a staff neonatologist and a neonatal nurse educator experienced in PIV placement and education, offered 3 training sessions conducted in October-November. Training involved a brief didactic session on IV placement based on current practice standards set by the Intravenous Nurses Society, ${ }^{15}$ followed by a demonstration on pediatric manikins. Total training time was one hour; the didactic portion consisted of a 15minute PowerPoint presentation and demonstration on manikins. The practice sessions lasted 30 minutes. The final check-off session lasted 15 minutes. We used Nita Newborn $^{\text {Tw }}$ (Laerdal, Wappingers Falls, NY) and a multi-venous IV training arm (Laerdal) for the training. Nine to 12 residents attended each session, offered during lunch hour (12-1 PM) on a weekday when there were no scheduled resident noon conferences.

\section{PIV competency checklist and follow-up surveys}

At the end of the didactic session, residents practiced IV placement on manikins. Each resident demonstrated IV placement technique on 1 of the manikins as assessed by 2 independent nurses experienced in PIV placement, using a checklist of steps based on hospital protocols. We did not ask residents to avoid previously used insertion sites. 
Residents selected the manikin of their choice, but since there were 2 infant and ladult arm manikin stations, the majority of residents attempted insertion on the infant manikin. Residents were unaware of the checklist steps. Nurses provided feedback on the skill following a failed attempt. If a resident was unsuccessful at placing a PIV at the first attempt, the nurse provided suggestions on how they could achieve success on their second attempt. The same nurses attended all 3 training sessions and used a checklist based on institution IV nursing protocol at our hospital (Appendix). The residents completed an immediate post-intervention survey following their training. Three months after the didactic and simulation session, participating residents received an online post-intervention survey.

\section{Outcomes}

Primary outcomes were successful completion of PIV training by correctly completing the PIV checklist as assessed by the nurses within 2 attempts. Success on the checklist was defined as the ability to successfully complete 9 out of 10 steps on the checklist, including completion of Step 8 (able to flush the IV catheter with normal saline). Therefore, if residents completed 9 out of 10 steps but were not able to flush the catheter (Step 8), they were not considered successful. Secondary outcomes were increased scores on self-reported knowledge, confidence, and success questions immediately after the intervention and at 3-month follow-up.

\section{Statistical analysis}

We used SAS v9.3 (SAS Institute Inc., Cary, NC) to perform data analysis. We expressed descriptive statistics as median and interquartile range for continuous variables and frequency and percentage for categorical variables, and presented the frequency and percentage of missing values. We compared the scores between any 2-paired surveys using the Wilcoxon signed-rank test (WSRT) to evaluate whether there was a significant change in the score. We used the bootstrapping method to estimate the median differences and corresponding interquartile ranges because there was no explicit form of the estimators for interquartile ranges. Spearman's rank correlation coefficients and their corresponding 95\% confidence intervals were estimated for evaluating the correlations between self-reported scores prior to the education session and prior training, perceived importance and long-term career plans, and experience, respectively. Based on Bonferroni adjustment for 3 pairwise comparisons, we considered p-values less than 0.017 $(0.05 / 3)$ to indicate statistical significance when interpreting the results from WSRTs.

\section{Results}

Forty-two residents out of 110 possible residents completed the pre-intervention survey. Thirty-two (76\%) finished the educational session and completed the survey given imme- diately after the session. Thirty-one (74\%) completed the survey 3 month after the educational session. Table 1 displays resident characteristics.

Table 1. Resident Characteristics: Baseline Survey $(\mathrm{N}=42)$

\begin{tabular}{|c|c|}
\hline Resident characteristics & $\mathrm{n}(\%)$ \\
\hline \multicolumn{2}{|l|}{ Residency year } \\
\hline Pediatric PGY1 & $11(26)$ \\
\hline Pediatric PGY2 & $14(33)$ \\
\hline Pediatric PGY3 & $12(29)$ \\
\hline Medicine-pediatrics & $5(12)$ \\
\hline \multicolumn{2}{|l|}{ Career goals } \\
\hline Outpatient pediatrics & $14(33)$ \\
\hline Hospitalist & $3(7)$ \\
\hline $\begin{array}{l}\text { Fellowship in a procedure-intensive field (NICU, PICU, } \\
\text { ER, Cardiology etc.) }\end{array}$ & $6(14)$ \\
\hline $\begin{array}{l}\text { Fellowship in a procedure non-intensive field (endo- } \\
\text { crine, behavioral pediatrics, adolescent medicine etc.) }\end{array}$ & $7(17)$ \\
\hline Undecided & $12(29)$ \\
\hline \multicolumn{2}{|l|}{ Prior training with PIV placement (before residency) } \\
\hline Residents reporting they had received training & $33(79)$ \\
\hline Residents reporting no prior training & $9(21)$ \\
\hline \multicolumn{2}{|l|}{$\begin{array}{l}\text { Prior experience with PIV placement before } \\
\text { residency }\end{array}$} \\
\hline None placed & $20(48)$ \\
\hline $1-5$ placed & $17(40)$ \\
\hline $6-10$ & $2(5)$ \\
\hline$>10$ & $3(7)$ \\
\hline \multicolumn{2}{|l|}{$\begin{array}{l}\text { Prior experience with PIV placement during } \\
\text { residency }\end{array}$} \\
\hline None placed & $26(62)$ \\
\hline $1-5$ placed & $6(14)$ \\
\hline $6-10$ & $3(7)$ \\
\hline$>10$ & $4(10)$ \\
\hline Missing values & $3(7)$ \\
\hline \multicolumn{2}{|l|}{ Perceived importance of PIV placement } \\
\hline Important or very important & $36(86)$ \\
\hline Somewhat important & $6(14)$ \\
\hline Not at all important & $0(0)$ \\
\hline \multicolumn{2}{|l|}{$\begin{array}{l}\text { Residents' opinion: best way to teach PIV skills to } \\
\text { residents }\end{array}$} \\
\hline Incorporate into PALS training & $10(23)$ \\
\hline $\begin{array}{l}\text { Combined nurse and resident training session at bed- } \\
\text { side }\end{array}$ & $32(76)$ \\
\hline Skills session at the beginning of each year & $21(50)$ \\
\hline Offer biannually as a noon conference session & $33(78)$ \\
\hline Online teaching module & $2(4)$ \\
\hline Other & $2(4)$ \\
\hline
\end{tabular}

The primary outcome of this study was the successful completion of PIV training by correctly demonstrating the steps in the checklist. Among the 32 residents who participated in the educational session, $30(94 \%)$ were successful in completing the checklist, while $2(6 \%)$ participants failed to complete the checklist successfully. Information on the number of attempts (i.e., 1 vs. 2 attempts) or the manikin used (Nita Newborn or Laerdal) by the resident was not collected. Twenty-eight residents demonstrated the ability to flush IV catheter with normal saline (Step 8) and success- 
fully completed 10 of 10 steps in the checklist. Two of the 30 successful residents completed Step 8 and missed 1 of 10 steps in the checklist. The missed steps included forgetting to apply the arm board (Step 3) and tourniquet removal after advancing catheter into vein (Step 7). Of the 2 residents considered unsuccessful, both were able to flush the IV catheter with normal saline (Step 8). One resident missed 2 of the 10 steps in the checklist including appropriately disposing the needle and securing the IV catheter. In this case, the resident applied the arm-board before sticking the manikin and did not tie the tourniquet appropriately. The other resident missed 4 of 10 steps, including selecting an appropriate site, inserting needle at an angle, withdrawing the needle and advancing the catheter in the vein, and securing the IV catheter. Only $7 \%$ of all residents reported they were 'confident' or 'very confident' with placing peripheral IVs at baseline (Figure 1). Of the 5 required 'emergent' procedures, endotracheal intubation, umbilical vessel catheterization, placement of intravenous lines, and placement of intraosseous lines, and basic and advanced life support, the lowest confidence was reported for PIV line placement.

The self-reported knowledge, confidence, and success scores for pre-intervention, immediate-after-intervention and 3-month follow-up surveys are summarized in Table 2 along with the estimated median differences, interquartile ranges, and p-values for testing the change in score between any 2 surveys. There was a statistically significant difference in participants' knowledge, confidence, and success scores immediately following the intervention and 3 months later; however, the overall self-reported confidence was still low and the median success scores remained unchanged (all pvalues < 0.017). In addition, residents' knowledge and confidence scores decreased 3 months after the session compared with the scores immediately after the session (both p-values=0.003).

Resident feedback on the educational session was positive. Twenty-nine (29) out of 31 residents stated they were more likely to attempt PIVs on real patients following the intervention, and that the didactic and practice sessions were useful. About one-third of the residents reported they would have preferred a bedside teaching session. Selfreported experience with PIV placement on real patients did not change significantly after the intervention [estimated median difference 0 , interquartile range $(0,0.87)$, $\mathrm{p}=0.05]$.

Table 3 shows the estimated correlation coefficients and their corresponding 95\% confidence intervals. PIV placement experience prior to residency was associated with higher knowledge, confidence, and success scores at baseline. Experience during residency was associated with higher knowledge and confidence scores. Interest in a procedural specialty was associated with greater selfreported experience with PIV placement (Table 4).
Table 2. Summary statistics for pre, immediate and 3-month follow-up surveys and pair-wise comparisons $(\mathrm{N}=42)$

\begin{tabular}{|c|c|c|c|}
\hline Variables & $\begin{array}{l}\text { Pre- } \\
\text { intervention }\end{array}$ & Immediate & $\begin{array}{l}\text { 3-month } \\
\text { Follow-up }\end{array}$ \\
\hline $\begin{array}{l}\text { Knowledge } \\
\mathrm{N} \\
\text { Median (Q1, Q3) }\end{array}$ & $\begin{array}{l}42 \\
1(0,2)\end{array}$ & $\begin{array}{l}32 \\
4(4,4)\end{array}$ & $\begin{array}{l}31 \\
4(3,4)\end{array}$ \\
\hline $\begin{array}{l}\text { Confidence } \\
\mathrm{N} \\
\text { Median (Q1, Q3) }\end{array}$ & $\begin{array}{l}42 \\
0(0,1)\end{array}$ & $\begin{array}{l}32 \\
1(1,2)\end{array}$ & $\begin{array}{l}31 \\
1(1,1)\end{array}$ \\
\hline $\begin{array}{l}\text { Success } \\
\mathrm{N} \\
\text { Median }(\mathrm{Q} 1, \mathrm{Q} 3)\end{array}$ & $\begin{array}{l}24 \\
1(0,2)\end{array}$ & --- & $\begin{array}{l}12 \\
1(1,2)\end{array}$ \\
\hline & \multicolumn{3}{|c|}{ Difference } \\
\hline Variables & $\begin{array}{l}\text { Immediate vs. } \\
\text { Pre }\end{array}$ & $\begin{array}{l}\text { Follow-up vs. } \\
\text { Immediate }\end{array}$ & $\begin{array}{l}\text { Follow-up vs. } \\
\text { Pre }\end{array}$ \\
\hline $\begin{array}{l}\text { Knowledge } \\
\mathrm{N} \\
\text { Median }(\mathrm{Q} 1, \mathrm{Q} 3)^{\dagger} \\
\text { P-value }\end{array}$ & $\begin{array}{l}32 \\
3(1.95,3.92) \\
<0.001^{\dagger \neq}\end{array}$ & $\begin{array}{l}31 \\
0(-0.77,0) \\
0.003^{\dagger \neq}\end{array}$ & $\begin{array}{l}31 \\
2(1.64,3.51) \\
<0.001^{\dagger \neq}\end{array}$ \\
\hline $\begin{array}{l}\text { Confidence } \\
\text { N } \\
\text { Median }(\mathrm{Q} 1, \mathrm{Q} 3) \\
\text { P-value }\end{array}$ & $\begin{array}{l}32 \\
1(1,1.29) \\
<0.001^{\dagger \neq}\end{array}$ & $\begin{array}{l}31 \\
0(-1,0) \\
0.003^{\dagger \neq}\end{array}$ & $\begin{array}{l}31 \\
1(0.15,1) \\
<0.001^{\dagger \ddagger}\end{array}$ \\
\hline $\begin{array}{l}\text { Success } \\
\mathrm{N} \\
\text { Median }(\mathrm{Q} 1, \mathrm{Q} 3) \\
\text { P-value }\end{array}$ & ---- & ---- & $\begin{array}{l}11 \\
1(0.50,1) \\
0.006^{\dagger \neq}\end{array}$ \\
\hline
\end{tabular}

${ }^{*}$ Q1 indicates the $1^{\text {st }}$ quartile $\left(25^{\text {th }}\right.$ percentile); Q3 indicates the $3^{\text {rd }}$ quartile $\left(75^{\text {th }}\right.$

percentile).
†ndicates statistical significance at a significance level of 0.017 .

\pm Q1 and Q3 of the difference were computed using the bootstrap sampling method.

Missing $N$ refers to the numbers of respondents who did not answer the question.

\section{Discussion}

This study demonstrated achievement of PIV competency among pediatrics residents on manikins at the end of a simulation-based training module. Scores of self-reported knowledge and confidence with PIV placement increased immediately after the intervention and at 3 months, but the overall confidence score post-intervention was still low, success scores did not improve, and there was a decline in scores at 3 months. Pediatrics residents perceived PIV skills as important to their training and reported nearly no confidence with this skill at baseline. Experience with PIV placement on real patients before and during residency positively correlated with knowledge and confidence scores. Residents who had placed more PIVs were likely to be interested in a procedural specialty.

A majority of pediatrics residents in our study felt it was important for them to learn PIV skills, yet self-reported confidence in PIV placement at baseline was low at all levels of training, a finding consistent with other studies. ${ }^{7,8,16}$ Confidence with placing central lines was also low and comparable to other studies. ${ }^{11}$ There is some evidence that medical students and housestaff in rural health settings perceive greater confidence in certain procedures, ${ }^{17-20}$ and that more procedures are performed by pediatricians in less densely populated regions, ${ }^{14}$ so it is possible that pediatrics residents in smaller, community-based settings are more confident placing PIVs; however, there are no data to support this. In some tertiary pediatric hospitals, alt-hough 
the responsibility of placing PIVs may not fall on the resident, residents expect to learn this skill.

Table 3. Correlation between residents' baseline scores of PIV knowledge, confidence, and success with PIV training and experience $(\mathrm{N}=42)$

\begin{tabular}{llll}
\hline \multirow{2}{*}{ Baseline score } & Knowledge & Confidence & Success \\
\cline { 2 - 4 } & $\begin{array}{l}\mathrm{Rho}^{*} \\
(95 \% \mathrm{Cl})\end{array}$ & $\begin{array}{l}\mathrm{Rho}^{*} \\
(95 \% \mathrm{Cl})\end{array}$ & $\begin{array}{l}\mathrm{Rho}^{*} \\
(95 \% \mathrm{Cl})\end{array}$ \\
\hline Prior training & 0.26 & 0.08 & 0.22 \\
& $(-0.05,0.52)$ & $(-0.23,0.37)$ & $(-0.20,0.57)$ \\
Perceived importance & 0.35 & 0.21 & 0.02 \\
& $(0.05,0.59)$ & $(-0.10,0.48)$ & $(-0.39,0.42)$ \\
Prior experience & 0.41 & 0.57 & 0.44 \\
(before residency) & $(0.12,0.64)$ & $(0.32,0.74)$ & $(0.05,0.72)$ \\
Current experience & 0.42 & 0.58 & 0.32 \\
(during residency) & $(0.12,0.65)$ & $(0.32,0.76)$ & $(-0.10,0.64)$ \\
\hline
\end{tabular}

${ }^{*}$ Rho indicates Spearman correlation coefficient. 95\% C.I stands for $95 \%$ confidence interval

Almost all residents were successful at completing the PIV competency checklist in our study. This was higher than that demonstrated in the study by Gaies, et al. ${ }^{10}$ In their study, success was defined as the ability to place an intravenous catheter on a manikin suitable for therapeutic infusion within 2 attempts. We defined our criteria to include successful infusion (flushing the catheter with saline) as well as the ability to perform at least 9 out of 10 checklist steps. Our higher checklist completion rate may be attributed to several reasons: participants were assessed on the same day as their training as opposed to 2 days after in their study, participants were provided feedback following failed attempt, and the training was offered as an informal 'noon conference' session, which may have led to lower performance anxiety.

Manikins, virtual reality devices, and traditional bedside teaching methods have all been used in IV placement training. ${ }^{21}$ Simulation devices afford a safe, effective and ethical way of teaching IV skills, and are of special use in the pediatric population. ${ }^{22-24} \mathrm{IV}$ training on manikins has shown to be superior to traditional bedside training in producing faster, more accurate and more professional placement on real patients. ${ }^{25}$ However, a study examining IV skills among nurses showed that vein variables (such as rolled vein) and patient variables (dark or tough skin, movement) are most likely to be associated with failed PIV insertion - both these constraints are typically circumvented in the manikin model. ${ }^{26}$ Newer virtual reality simulators provide a threedimensional, self-directed learning environment, and have shown to be at least as effective, if not superior to manikins in producing successful intravenous insertions on real patients. ${ }^{27,28}$ However, these devices are expensive, and user satisfaction and knowledge gains are reported to be higher with the manikins than with virtual reality devices. ${ }^{29}$

Among pediatrics residents, 2 studies have shown success with central venous (but not peripheral intravenous skills) and intraosseous skills in the context of mock code scenarios using simulation-based teaching modules. ${ }^{7,8}$ One of these studies measured resident self-report following an intervention but did not test for competency. ${ }^{7}$ Only one study has looked at simulation as a tool in specifically improving PIV skills among pediatrics residents. ${ }^{10}$ This study showed an increase in knowledge scores and PIV competency on manikins initially, but not at follow-up, and no improvement in skills on real patients. Our limited study demonstrates that following a simulation-based training session, residents were successfully able to place peripheral intravenous lines on manikins; however, we did not measure baseline competency, and many residents had received training in PIV placement prior to residency. Our results underscore the limitations of the simulation model in the context of PIV training, in that although it may be a good primer in increasing knowledge and confidence, it alone may not be sufficient in acquiring competency.

Table 4.PIV Experience during residency and long-term career choice $(\mathrm{N}=42)$

\begin{tabular}{|c|c|c|c|c|c|}
\hline \multirow{2}{*}{$\begin{array}{l}\text { Long-term } \\
\text { career plan }\end{array}$} & \multicolumn{5}{|c|}{$\begin{array}{l}\text { Experience during Residency } \\
\text { (Number of PIVs placed) }\end{array}$} \\
\hline & $\begin{array}{l}\text { None } \\
\mathrm{n}(\%)\end{array}$ & $\begin{array}{c}1-5 \\
n(\%)\end{array}$ & $\begin{array}{c}6-10 \\
n(\%)\end{array}$ & $\begin{array}{l}>10 \text { run } \\
\mathrm{n}(\%)\end{array}$ & $\begin{array}{c}\text { Total } \\
\mathrm{n}\end{array}$ \\
\hline $\begin{array}{l}\text { Outpatient } \\
\text { Pediatrics }\end{array}$ & $9(64)$ & $4(29)$ & $0(0)$ & $1(7)$ & 14 \\
\hline Hospitalist & $1(33)$ & $0(0)$ & $2(67)$ & $0(0)$ & 3 \\
\hline $\begin{array}{l}\text { Fellow- } \\
\text { ship(non- } \\
\text { procedural } \\
\text { field) }\end{array}$ & $7(100)$ & $0(0)$ & $0(0)$ & $0(0)$ & 7 \\
\hline $\begin{array}{l}\text { Fellowship } \\
\text { (procedural } \\
\text { field) }\end{array}$ & $0(0)$ & $2(33)$ & $1(17)$ & $3(50)$ & 6 \\
\hline Undecided & $9(100)$ & $0(0)$ & $0(0)$ & $0(0)$ & 9 \\
\hline Missing & & & & & 3 \\
\hline Total & 26 & 6 & 3 & 4 & 42 \\
\hline
\end{tabular}

Experience with PIV on real patients, both before and during residency, was associated with higher scores of knowledge and confidence at baseline, emphasizing that experience on real patients may be the most important factor in retention of clinical skills. As an example, perceived confidence reported with lumbar puncture, a procedure performed almost exclusively by residents, was high, although we provide no formal training for this procedure at our institution, except for traditional bedside teaching. Several studies have demonstrated an improved procedural knowledge and confidence score following simulationbased training. ${ }^{10,22,30}$ However, one study on neonatal endotracheal intubation among pediatrics residents showed that although simulation leads to increase in immediate knowledge scores, it does not lead to improved performance on real patients and maybe falsely reassuring. ${ }^{31}$

Our results show that although residents perceived themselves to be more likely to place PIVs on real patients following a simulation-based teaching session, self-reported 
experience on real patients does not significantly change at 3 months perhaps because of the limited opportunities to place PIVs at our institution. Our residents' experience with PIVs may be enhanced by changes in institutional policy, for example, after appropriate didactic and simulated training, requiring residents to place PIVs when they are on call on inpatient services with supervision from nurses.

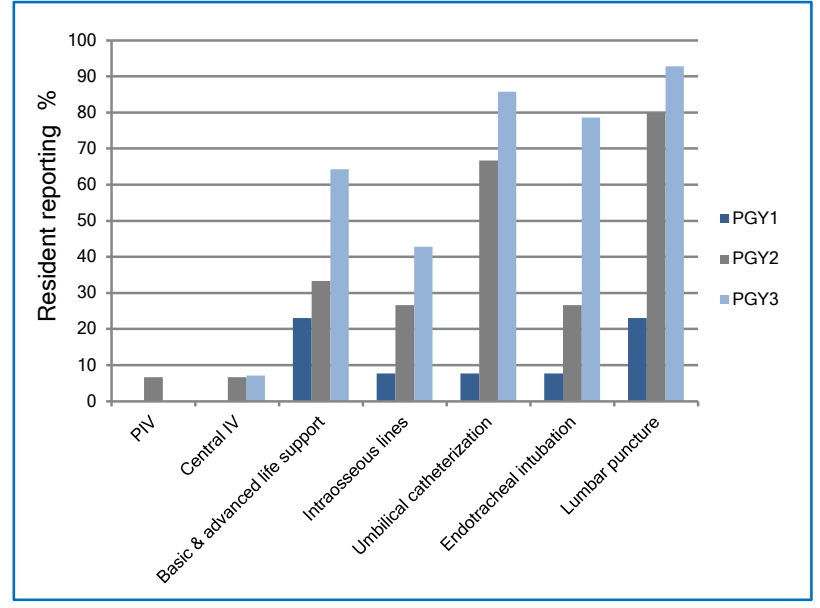

Figure 1. Percent residents reporting 'confident' or 'very confident' with ACGME procedures $(\mathrm{N}=42)$

\section{Limitations}

Our study has several limitations. This was a single institution study with a small sample size in a tertiary children's hospital, and the results may not be generalizable to other centers. We used a single group, pre- and post-study design, and a convenience sample of residents, which may have led to selection bias; it is possible that only those residents who perceived they had poor PIV skills participated, leading to a falsely low confidence level at baseline. Measures for knowledge, confidence, and success were not assessed for reliability or validity and relied only on self-report. We did not reassess PIV competency on manikins at baseline or at 3-month follow-up, only self-reported scores of knowledge, confidence, and success. Residents' competency on real patients was not assessed in our study; the pediatric manikins had clearly visible veins; the experience of locating and successfully inserting an IV in a real child with poorly visible or collapsed veins in the presence of an anxious parent is more challenging.

\section{Conclusion}

Besides being a common and useful skill in pediatric practice, PIV placement remains an ACGME procedural competency in the United States. Pediatrics residents' confidence and experience with this skill is lower than any other required skill, and residents desire structured training. This study demonstrates the usefulness and limitations of simulation in PIV training. A simulated session increases self-reported PIV knowledge and confidence scores at 3 months, but overall confidence score remains low. Training on manikins does not increase success scores. Such training may prepare residents for real-life experience and increase perceived confidence with this skill, but changes in institution policy that will allow opportunities for residents to routinely place PIVs in the work environment are necessary.

\section{Acknowledgments}

We are thankful to the pediatrics residency program leadership at Arkansas Children's Hospital for their support, the PULSE simulation center for providing necessary equipment, and to Lacey Begnaud, RN, and Amanda Lobbs, RN, who agreed to be our independent observers.

\section{Conflict of Interest}

The authors declare that they have no conflict of interest.

\section{References}

1. Coberly L, Goldenhar LM. Ready or not, here they come: acting interns' experience and perceived competency performing basic medical procedures. J Gen Intern Med. 2007;22(4):491-4.

2. Mason WT, Strike PW. See one, do one, teach one--is this still how it works? A comparison of the medical and nursing professions in the teaching of practical procedures. Med Teach. 2003;25(6):664-6.

3. ACGME Program Requirements for Graduate Medical Education in Pediatrics. 2013 [cited 8 Nov 2012]; Available from: https://www. acgme.org/acgmeweb/Portals/0/PDFs/archive/320_pediatrics_PRs_RC.pdf. 4. Stolarek I. Procedural and examination skills of first-year house surgeons: a comparison of a simulation workshop versus 6 months of clinical ward experience alone. N Z Med J. 2007; 120(1253):U2516.

5. Moercke AM, Eika B. What are the clinical skills levels of newly graduated physicians? Self-assessment study of an intended curriculum identified by a Delphi process. Med Educ. 2002;36(5):472-8.

6. Goodfellow PB, Claydon P. Students sitting medical finals--ready to be house officers? J R Soc Med. 2001;94(10):516-20.

7. Cappelle C, Paul RI. Educating residents: the effects of a mock code program. Resuscitation.1996;31(2):107-11.

8. Nadel FM, Lavelle JM, Fein JA, Giardino AP, Decker JM, Durbin DR. Assessing pediatric senior residents' training in resuscitation: fund of knowledge, technical skills, and perception of confidence. Pediatr Emerg Care. 2000;16(2):73-6.

9. Gaies MG, Landrigan CP, Hafler JP, Sandora TJ. Assessing procedural skills training in pediatric residency programs. Pediatrics. 2007;120(4):71522.

10. Gaies MG, Morris SA, Hafler JP, Graham DA, Caspraro AJ, Zhou J, et al. Reforming procedural skills training for pediatric residents: a randomized, interventional trial. Pediatrics. 2009;124(2):610-9.

11. Reuben DB, McCue JD, Gerbert B. The residency-practice training mismatch: a primary care education dilemma. Arch Intern Med.1988;148(4):914-9.

12. Camp BW, Gitterman B, Headley R, Ball V. Pediatric residency as preparation for primary care practice. Arch Pediatr Adolesc Med.1997;151(1):78-83.

13. Oliver TK, Jr., Butzin DW, Guerin RO, Brownlee RC. Technical skills required in general pediatric practice. Pediatrics.1991;88(4):670-3.

14. Feigin RD, Drutz JE, Smith EO, Collins CR. Practice variations by population: training significance. Pediatrics.1996;98(2 Pt 1):186-90.

15. Infusion Nurses Society. Infusion Nursing Standards of Practice. J Infus Nurs. 2006;29(1 Suppl):S1-92.

16. Evans DE, Wood DF, Roberts CM. The effect of an extended hospital induction on perceived confidence and assessed clinical skills of newly qualified pre-registration house officers. Med Educ. 2004;38(9):998-1001. 17. Worley P, Strasser R, Prideaux D. Can medical students learn specialist disciplines based in rural practice: lessons from students' self reported experience and competence. Rural Remote Health. 2004;4(4):338. 
18. Goertzen J. Learning procedural skills in family medicine residency: co mparison of rural and urban programs. Can Fam Physician. 2006;52:622-3.

19. Engum SA. Do you know your students' basic clinical skills exposure? Am J Surg. 2003;186(2):175-81.

20. Verby JE, Newell JP, Andresen SA, Swentko WM. Changing the medical school curriculum to improve patient access to primary care. JAMA.1991;266(1):110-3.

21. Seropian MA, Brown K, Gavilanes JS, Driggers B. Simulation: not just a manikin. J Nurs Educ. 2004;43(4):164-9.

22. Langhan TS, Rigby IJ, Walker IW, Howes D, Donnon T, Lord JA. Simulation-based training in critical resuscitation procedures improves residents' competence. CJEM. 2009;11(6):535-9.

23. Weinberg ER, Auerbach MA, Shah NB. The use of simulation for pediatric training and assessment. Curr Opin Pediatr. 2009;21(3):282-7.

24. Nadel FM, Lavelle JM, Fein JA, Giardino AP, Decker JM, Durbin DR. Teaching resuscitation to pediatric residents: the effects of an intervention. Arch Pediatr Adolesc Med. 2000;154(10):1049-54.

25. Lund F, Schultz JH, Maatouk I, Krautter M, Moltner A, Werner A, et al. Effectiveness of IV cannulation skills laboratory training and its transfer into clinical practice: a randomized, controlled trial. PloS one. 2012;7(3):e32831.
26. Jacobson AF, Winslow EH. Variables influencing intravenous catheter insertion difficulty and failure: an analysis of 339 intravenous catheter insertions. Heart Lung. 2005;34(5):345-59.

27. Chang KK, Chung JW, Wong TK. Learning intravenous cannulation: a comparison of the conventional method and the CathSim Intravenous Training System. J Clin Nurs. 2002;11(1):73-8.

28. Bowyer MW, Pimentel EA, Fellows JB, Scofield RL, Ackerman VL, Horne PE, et al. Teaching intravenous cannulation to medical students: comparative analysis of two simulators and two traditional educational approaches. Stud Health Technol Inform. 2005;111:57-63.

29. Engum SA, Jeffries P, Fisher L. Intravenous catheter training system: computer-based education versus traditional learning methods. Am J Surg. 2003;186(1):67-74.

30. Millington SJ, Wong RY, Kassen BO, Roberts JM, Ma IW. Improving internal medicine residents' performance, knowledge, and confidence in central venous catheterization using simulators. J Hosp Med. 2009;4(7):4106.

31. Finan E, Bismilla Z, Campbell C, Leblanc V, Jefferies A, Whyte HE. Improved procedural performance following a simulation training session may not be transferable to the clinical environment. J Perinatol. 2012;32(7):539-44. 